DOI: http://dx.doi.org/10.33846/hn40903

http://heanoti.com/index.php/hn

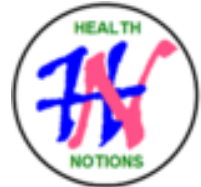

RESEARCH ARTICLE

URL of this article: http://heanoti.com/index.php/hn/article/view/hn40903

\title{
Behavioral Consequences of Alcohol Use Among Students of Isabela State University - Main Campus
}

\author{
Edmelyn B. Cacayan ${ }^{1}$, Queenie B. Solatre², Mark Hipolito P. Galingana ${ }^{3(\mathrm{CA})}$ \\ ${ }^{1}$ Dean, Isabela State University, College of Nursing, Philippines \\ ${ }^{2}$ Nursing Graduate, Isabela State University, College of Nursing, Echague, Isabela, Philippines \\ ${ }^{3(\mathrm{CA})}$ Isabela State University, College of Nursing, Echague, Isabela, Philippines; markgalingana@ gmail.com \\ (Corresponding Author)
}

\begin{abstract}
The study was focused on the behavioural consequences state of alcohol use among the students. The respondents were all levels of students of Isabela State University-Main Campus. The researcher used survey questionnaire and interview to gather data. The study found out that the majority of the respondents were under 19-20 years old, male, junior with allowance of 100-200 pesos per day. The Behavioral Consequences on Alcohol Use Among Students of Isabela State University-Main Campus were the following: First was the Profile of the Respondents, followed by the Awareness of the Respondents on Alcohol, Behavioral Consequences of Alcohol and lastly the Leading Factors on Using Alcohol. Based on the above conclusions, the following recommendations were: Clinicians are important to screen students of Isabela State University-Main Campus for alcohol misuse and provide persons engaged in risky or hazardous drinking with behavioral counselling interventions to reduce alcohol misuse. That those who do not consume alcoholic beverages should not start doing so because of the negative impact. Provide Educational Programs among Isabela State University-Main Campus students to enhance their knowledge about alcohol consumption. Since the majority of respondent were 19-20 years old, a similar study should be conducted regarding other possible behavioral consequences, awareness and factors on alcohol and should also be conducted with larger number of respondents.
\end{abstract}

Keywords: behavioral consequences; alcohol use; students

\section{INTRODUCTION}

Alcohol is one of the most widely used substances in the world. Alcohol use is not only an adult problem. Most are college students engaged in drinking alcohol, despite the fact that the legal drinking age is 21 years old. As in the general population, the excessive use of alcohol by youths and young adults creates adverse outcomes in both the short and long run. Some particularly concerning negative alcohol related outcomes for the young population include: risky sexual behavior (often leading to unplanned pregnancies, birth defects, human immunodeficiency virus and other sexually transmitted adult diseases); lower levels of human capital acquisition (educational attainment and career advancement); interpersonal and family violence (rape, sexual abuse and physical assault); criminal activities (theft and vandalism); increased risk of alcohol poisoning and overdosing; increased risk-taking and sensation-seeking behavior (drunk driving). (NIAAA, 1997) Indeed, alcohol is one of the most costly legal substances consumed in the United States. In 1998, the estimated cost of alcohol use amounted to $\$ 185$ billion. Of this total, fourteen percent was used to pay for alcohol related health care and medical treatment, fourthly seven percent (47\%) was lost to decreased worker productivity, and twenty percent (20\%6) was attributed to premature deaths due to (three) alcohol use and eighteen percent (18\%) of costs are associated with crime and alcohol related traffic accidents ${ }^{(1)}$.

Expanding our understanding of the alcohol use and potential health benefits remains a challenge and although there are positive effects, alcohol may not benefit everyone who drinks.

A survey focusing on the alcohol-related problems experienced by 4,390 high school seniors and dropouts found that within the preceding year, approximately 80 percent reported either getting "drunk," binge drinking, or drinking and driving. More than half said that drinking had caused them to feel sick, miss school or work, get arrested, or have a car $\mathrm{crash}^{(3)}$. Some adolescents who drink later abuse alcohol and may develop 
alcoholism. Although these conditions are defined for adults in the DSM, research suggests that separate diagnostic criteria may be needed for youth.

Surveys of adolescents suggest that alcohol use is associated with risky sexual behavior and increased vulnerability to coercive sexual activity. Among adolescents surveyed in New Zealand, alcohol misuse was significantly associated with unprotected intercourse and sexual activity before age $16^{(4)}$. Forty-four percent of sexually active Massachusetts teenagers said they were more likely to have sexual intercourse if they had been drinking, and 17 percent said they were less likely to use condoms after drinking ${ }^{(5)}$.

Survey results from a nationally representative sample of 8th and 10th graders indicated that alcohol use was significantly associated with both risky behavior and victimization and that this relationship was strongest among the 8th-grade males, compared with other students ${ }^{(6)}$. High doses of alcohol have been found to delay puberty in female ${ }^{(7)}$ and male rats ${ }^{(8)}$, and large quantities of alcohol consumed by young rats can slow bone growth and result in weaker bones ${ }^{(9)}$. However, the implications of these findings for young people are not clear.

Hence these observed dilemmas fuels the researchers to conduct this undertaking on examining the behavioral consequences of alcohol use among students of Isabela State University - Main Campus.

\section{METHODS}

The research design used was the descriptive normative survey design. The descriptive method sought to find the answers to questions through the analysis of relationships among variables. It is used to classify a number of different types of activities. It includes document or content analysis, explanatory and observational studies. This design was best used when the researcher wants to quantify and expressly describe nominal characteristic for better understanding of the problem in the study. The type of quantitative design in this study is non-experimental. In this design, observation of certain characteristics and behaviors explained the problem of the research.

The locale of the study was at Isabela State University-Main Campus. The respondents of the study were the students enrolled in the school year 2015- 2016 in Isabela State University-Main Campus. Specifically, there were 10 randomly selected students coming from each of the 9 colleges of Isabela State University-Main Campus (CON, CAS, IICT, CA, CE, CBAPA, SVM, COF, CTE ). The total sample size was 90.

The researcher used a questionnaire adapted from the Missippi State University Alcohol Awareness Survey with some revisions, the Questionnaire had 4 parts. The first part was the demographic profile of the respondents. The second part was the Respondents Awareness on alcohol followed by part 3 about the Behavioral Consequences of the respondents and lastly part 4 was the Leading factors of the respondents to drink. The purpose of the questionnaire was to gather information from the respondents.

The gathered data were tallied, summarized and treated using descriptive statistics to answer the specific questions, the specific statistical analyses used were the frequency counts, percentage and weighted mean.

1. Percentage is used to determine definite proportion of the responses by given respondents. It is done by dividing the frequency o9f the respondents by the total number of respondent. The formula is:

$\mathrm{f} / \mathrm{n} \times 100 \%$

Where:

$\%=$ percentage

$\mathrm{f}=$ frequency of responses

$\mathrm{n}=$ total number of respondents

2. Weighted Mean (x) - by weighted mean, the weighted mean responses are estimated in relation to the total response. It is calculated by adding all scores and dividing the sum by all the number of scores. The formula is:

$\mathrm{X}=\mathrm{fx} / \mathrm{N}$

Where:

$\mathrm{X}=$ weight assigned to each response

$\mathrm{f}=$ frequency of responses

$\mathrm{n}=$ total frequency

3. The criteria will be translated on the following verbal interpretation based on the Likert's scale. The following scales and verbal interpretations will used in the instrument in determining the behavioral consequences of alcohol among students of Isabela State University-Main Campus.

Table 1. Verbal interpretation based on the Likert's scale (2 categories)

\begin{tabular}{ccc}
\hline Scale & Range & Verbal interpretation \\
\hline 2 & $1.5-2.49$ & False \\
\hline 1 & $1.00-1.49$ & True \\
\hline
\end{tabular}


For better analysis and interpretation of the results, the researcher will be guided with a scale of 1-2.49 is use with the ranges of weight and their corresponding interpretation. An arbitrary value of I range from 1.00 to 1.49 with a description of True and an arbitrary value of 2 ranges from 1.5 to 2.49 with a description of False.

Table 2. Verbal interpretation based on the Likert's scale (5 categories)

\begin{tabular}{ccc}
\hline Scale & Range & Verbal interpretation \\
\hline 5 & $4.5-5.00$ & 10 or more \\
\hline 4 & $3.5-4.49$ & $6-9$ times \\
\hline 3 & $2.5-3.49$ & $3-5$ time \\
\hline 2 & $1.5-2.49$ & $1-2$ time \\
\hline 1 & $1.00-1.49$ & None \\
\hline
\end{tabular}

For better analysis and interpretation of the results, the researcher will be guided with a scale of 1-5 use with the ranges of weight and their corresponding interpretation. An arbitrary value of 1 range from 1.00 to 1.49 with a description of None, an arbitrary value of 2 ranges from 1.5 to 2.49 with a description of 1-2 times, an arbitrary value of 3 ranges from 2.5 to 3.49 with a description of 3-5 times, an arbitrary value of 4 ranges 3.5 to 449 with a description of 6-9 times and an arbitrary value of 5 ranges 4.5-5 with a description of 10 or more.

\section{Profile of the Respondents}

\section{RESULTS}

Table 3. Frequency and percentage distribution of the respondents profile according to age

\begin{tabular}{ccc}
\hline Age & Frequency & Percentage \\
\hline $19-20$ & 49 & 54.40 \\
\hline 21 and above & 23 & 25.60 \\
\hline $17-18$ & 18 & 20.00 \\
\hline Total & 90 & 100.00 \\
\hline
\end{tabular}

Table 3 presents the age bracket of the respondents which includes 17-18 years old which has a frequency of 18 in population and a total of $20 \%$ of the respondents. While for the age of 19-20 years old the population is 49 and this contains the total of $54.4 \%$. In the age bracket of 21 and above the population is 23 and contains the $25.6 \%$ of the respondents.

Table 4. Frequency and percentage distribution of the respondents profile according to gender

\begin{tabular}{ccc}
\hline Gender & Frequency & Percentage \\
\hline Male & 57 & 63.30 \\
\hline Female & 33 & 36.70 \\
\hline Total & 90 & 100.00 \\
\hline
\end{tabular}

Table 4 shows that according to gender, for male, a total frequency of 57 ; this represents the $63.3 \%$ of the respondents. Whereas for female, there were 33 in frequency and this comprises the $36.7 \%$ the total respondents.

Table 5. Frequency and percentage distribution of the respondents profile according to year level

\begin{tabular}{ccc}
\hline Year level & Frequency & Percentage \\
\hline Junior & 41 & 45.60 \\
\hline Senior & 29 & 32.20 \\
\hline Sophomore & 17 & 18.90 \\
\hline Freshman & 3 & 3.30 \\
\hline Total & 90 & 100.00
\end{tabular}

In the year level distribution, the junior level has the highest frequency of 41 and contains a total percentage of $45.6 \%$. While the senior level has a frequency of 29 and a total percentage of $32.2 \%$ fallowed by sophomore level with a frequency of 17 and a total percentage of $18.9 \%$ and lastly the freshman level a frequency of 3 and contains a total percentage of $3.3 \%$ 
Table 6. Frequency and percentage distribution of the respondents profile according to allowance per day

\begin{tabular}{ccc}
\hline Allowance per day & Frequency & Percentage \\
\hline $100-200$ & 57 & 63.30 \\
\hline $201-300$ & 19 & 20.00 \\
\hline $301-400$ & 14 & 14.40 \\
\hline 401 and above & 2 & 2.30 \\
\hline Total & 90 & 100.00 \\
\hline
\end{tabular}

In the allowance distribution, the highest belongs to 100-200 pesos per day which has a frequency of 57 and a total percentage of $63.3 \%$; fallowed by $201-300$ pesos per day with a frequency of 18 or percentage of $20 \%$, followed by 301- 400 pesos per day frequency of 13 and a percentage of $14.4 \%$, and the least is $401-500$ pesos per day with frequency of 2 and percentage contains $2.2 \%$ of the respondents which was 90 .

Table 7. Profile of the respondents' according to background on alcohol use

\begin{tabular}{lcl}
\hline Items & Mean & \multicolumn{1}{c}{ Interpretation } \\
\hline Do you ever drink alcohol? & 1.06 Yes \\
\hline At what age did you start alcohol? & 1.96 & $15-17$ years old \\
\hline Do you feel you are normal drinker? & 1.0 & No \\
\hline How often do you drink alcohol? & 3.19 Once a week \\
\hline Do you engage in binge drinking? & 1.58 No \\
\hline Estimate the number of hours you drank the last time you socialized & 3.12 & $2-3$ hours \\
\hline How many bottles did you have that time? & 2.80 & $3-4$ hours \\
\hline In the last two weeks, how many times have you had bottle at a sitting? & 2.29 & $1-3$ bottles at a sitting \\
\hline How many days in a week do you engage in drinking spree? & $2.21 \quad 1-2$ days \\
\hline
\end{tabular}

Table 7 shows that in terms of alcohol use, the respondents claimed that they all drink alcohol (1.06). The age bracket of 15-17 years old (1.96) they start using alcohol. With the mean of 1.86 and most of them stated that no one influenced them to drink; they just feel bored. The respondents claimed that they are not normal drinker (1.30). Based on question given on how they often to drink, the respondents answered once a week (3.19). With the mean of 1.58 the respondents they are not engage in binge drinking. In estimating the number of hours they drank the last time they socialized, they answered 2-3hours (3.1). 3 to 4 bottles did they drink at last time they socialized (2.80). In last 2 weeks they had 1 to 3 bottles at a sitting (2.29) and 1to 2 days in a week the respondents engage in drinking spree (2.21).

\section{Awareness of the Respondents on Their Use of Alcohol}

Table 8. Respondents' awareness on alcohol

\begin{tabular}{lcc}
\hline Items & Mean & Interpretation \\
\hline A person cannot become an alcoholic by just drinking a beer. & 1.39 & True \\
\hline Many people drink to escape from problems. & 1.38 & True \\
\hline $\begin{array}{l}\text { Responsible drinking can result in relaxation, enhanced social interactions, and a } \\
\text { feeling of well- being. }\end{array}$ & 1.30 & True \\
\hline Alcoholic beverages contain weight- increasing calories. & 1.26 & True \\
\hline Alcohol is use usually classified as a stimulant. & 1.23 & True \\
\hline $\begin{array}{l}\text { Many acceptance, because of peer group people drink for social pressures, and to } \\
\text { gain adult status. }\end{array}$ & 1.22 & True \\
\hline Consumption of alcoholic beverages is generally not harmful to the body. & 1.13 & True \\
\hline Alcohol is not a drug. of fatal & 1.10 & True \\
\hline Approximately highway $10 \%$ accidents are alcohol related. & 1.09 & True \\
\hline $\begin{array}{l}\text { It is estimated that approximately } 85 \% \text { of the adult who drink misuse alcoholic } \\
\text { beverages. }\end{array}$ & 1.09 & True \\
\hline
\end{tabular}

Table 8 shows that in terms of knowledge of Isabela State University- Main Campus students about alcohol use, all of the respondents answered true that alcohol is not a drug (1.06), not provide weight-increasing calories (1.20), approximately $10 \%$ of fatal highway accidents are alcohol related (1.09), estimated that approximately $85 \%$ of the adult who drink misuse or abuse alcoholic beverages (1.09), a person cannot become 
an alcoholic by just drinking a beer (1.39), many people drink to escape from problem , loneliness and depression (1.38), responsible drinking can result in relaxation, enhanced social interactions and a feeling of well-being (1.30), that alcohol is use usually classified as a stimulant (1.23), consumption of alcoholic beverages is generally because of peer not harmful (1.13), many people drink for social acceptance group pressures and to gain adult status (1.22).

\section{Respondents' Adverse Behavioural Consequences of Drinking Alcohol}

Table 9. Respondents' behavioral consequences of alcohol use

\begin{tabular}{lll}
\hline Items & Mean & Interpretation \\
\hline Being drowsy & 1.77 & $1-2$ times \\
\hline Missed a class & 1.73 & $1-2$ times \\
\hline Slurred speech & 1.50 & $1-2$ times \\
\hline Being involved in an argument & 1.47 & None \\
\hline Being hurt or injured & 1.43 & None \\
\hline Being involved in fight & 1.38 & None \\
\hline Risky sexual behavior & 1.37 & None \\
\hline Performed poorly on a test & 1.36 & None \\
\hline Damaged property & 1.30 & None \\
\hline Being physical violent & 1.22 & None \\
\hline
\end{tabular}

Table 9 shows that in terms of Behavioral Consequences of alcohol use, the respondents stated that they experienced missing a class (1.73), being drowsy (1.77) and having a slurred speech (1.5) one to two times after drinking alcohol. Majority of the respondents answered that they never experienced some of the consequences such as performing poorly on a test (1.36), damaging a property (1.30), being physically violent (1.20), being hurt or injured (1.43), having a risky sexual behavior (1.37), being involved in an argument (1.47) and being involved in a fight (1.38).

\section{Factors that Lead Respondents to Drink}

Table 10. Factors that lead the respondents to drink

\begin{tabular}{lll}
\hline Items & Mean & Interpretation \\
\hline Family Factors & & \\
\hline Are you misguided by your parents? & 1.82 & No \\
\hline Do you drink because you lost a family member? & 1.76 & No \\
\hline Do you have a family problem? & 1.58 & No \\
\hline Personal Factors & 1.39 & \\
\hline Are you with a broken relationship? & 1.39 & Yes \\
\hline Do you drink because you are tired? & 1.37 & Yes \\
\hline Have you failed in one of your examinations? & 1.36 & Yes \\
\hline Do you drink because you are happy? & 1.28 & Yes \\
\hline Are you stressed of many school requirements & 1.26 & Yes \\
\hline Are you influenced by your friends? & & \\
\hline
\end{tabular}

In terms of factors that lead the respondents to drink, it is classified into two; family factors and personal factors. The respondents answered that the family factors are not leading factor. That they don't have any family problem (1.58), they didn't lose a family member (1.76) and they are not misguided by their parents. Majority of the respondent fall under personal factors which lead them to drink. They drink because they are having a broken relationship (1.39), they just drink because they are tired (1.39), they failed in one of their examinations (1.37), they drink because they are happy (1.36), stressed from many school requirements (1.28) and lastly, they drink because they are being influenced by their friends or peers.

\section{DISCUSSION}

It is note taking that alcohol use, the respondents claimed that they all drink alcohol. The age bracket of 15-17 years old it is when they start using alcohol. Most of them stated that no one influenced them to drink; they just feel bored. students about alcohol use, all of the respondents perceived that alcohol is not a drug, and it 
does not provide weight-increasing calories, approximately $10 \%$ of fatal highway accidents are alcohol related, It is estimated that approximately $85 \%$ of the adult who drink misuse or abuse alcoholic beverage. The respondents also perceived that a person cannot become an alcoholic by just drinking a beer occasionally, other perceived that many people drink to escape from problem, loneliness and depression, It is often noted that responsible drinking can result in relaxation, enhanced social interactions and a feeling of well-being. This study also divulges that factors which lead the respondents to drink are classified into two; family factors and personal factors. The respondents answered that the family factors are not leading factor that leads them in drinking or consuming alcohol.

\section{CONCLUSION}

Based on the findings, the researcher therefore concludes that: The demographic of the respondents revealed the following: Most of the respondents are ages 19-20 years old, male, junior with allowance of 100200 pesos per day; All the respondents were drinking alcoholic beverages. Majority of them started at the age ranging from 15-17 and they stated that no one influenced them to drink. They just drink because of boredom. Most of them felt like they are already abusers. The respondents were only drinking once a week that last for 2-3 hours with 3-4 bottles. Most of the respondents do not engage in binge drinking. The results showed that the respondents were not fully aware on the effect of drinking alcohol. This implies that they just drink for no reason at all. Based on the findings, the respondents claimed that they experienced various behavioural consequences when they use alcohol. Based on the results of interview it showed that majority of the respondents were not affected with factors related to family problems. This implies that none of the respondents engaged to binge alcohol drinking were not really affected with any family related factors.

Based on the above conclusions, the following are the recommendations: Clinicians are important to screen students of Isabela State University-Main Campus for alcohol misuse and provide persons engaged in risky or hazardous drinking with behavioral counselling interventions to reduce alcohol misuse. That those who do not consume alcoholic beverages should not start doing so because of the negative. Provide Educational Programs among Isabela State University-Main Campus students to enhance their knowledge about alcohol consumption. Since the majority of respondent were 19-20 years old, a similar study should be conducted regarding other possible behavioral consequences, awareness and leading factors on alcohol and should also be conducted with larger number of respondents.

\section{REFERENCES}

1. National Institute on Alcohol Abuse and Alcoholism. Alcohol Use Disorder: A Comparison Between DSMIV and DSM-5. 2013. Available from: https://www.niaaa.nih.gov/publications/brochures-and-factsheets/alcohol-use-disorder-comparison-between-dsm

2. University of Michigan. The rise in drug use among American teens continues in 1996. News and Information Services press release [early release of results from annual Monitoring the Future Study. 1996.

3. Ellickson PL, et al. Teenagers and alcohol misuse in the United States: By any definition, it's a big problem. Addiction. 1996;91(10):1489-1503.

4. Fergusson DM, Lynskey MT. Alcohol misuse and adolescent sexual behaviors and risk taking. Pediatrics. 1996:98(1):91-96.

5. Strunin L, Hingson R. Alcohol, drugs, and adolescent sexual behavior. International Journal of the Addictions. 1992;27(2):129-146,

6. Windle M. Substance use, risky behaviors, and victimization among a US national adolescent sample. Addiction. 1994;89:175-182.

7. Dees WL, Skelley CW. Effects of ethanol during the onset of female puberty. Neuroendocrinology. 1990;5:64-69.

8. Cicero TJ, et al. Influence of chronic alcohol administration on representative indices of puberty and sexual maturation in male rats and the development of their progeny. The Journal of Pharmacology and Experimental Therapeutics. 1990;255(2):707-715.

9. Sampson HW, et al. Alcohol consumption inhibits bone growth and development in young actively growing rats. Alcoholism: Clinical and Experimental Research. 1996:20(8):1375-1384. 